\title{
Risk and school science education
}

\section{Clare Christensen}

Faculty of Education, Griffith University, Brisbane, Australia 


\section{Abstract}

In this paper I consider a role for risk understanding in school science education. Grounds for this are described in terms of current sociological analyses of the contemporary world as a 'risk society' and recent public understanding of science studies where science and risk are concerns commonly linked within the wider community. These concerns connect with support amongst many science educators for the goal of science education for citizenship. From this perspective scientific literacy for decision making on contemporary socioscientific issues is central. I argue that in such decision making risk understanding has an important role to play. I examine some of the challenges its inclusion in school science presents to science teachers, review previous writing about risk in the science education literature and consider how knowledge about risk might be addressed in school science. I also outline the varying conceptions of risk and suggest some future research directions which would support the inclusion of risk in classroom discussions of socioscientific issues.

\section{Risk and school science education}

Science has long been presented as a highly reliable (if not 'certain') body of knowledge which has the capacity to provide explanations for phenomena and solve practical problems. Recent social theorists such as Beck and Giddens, however, have argued that, alongside solutions to some problems, science and its 
associated products and technologies increasingly challenge people with new uncertainties and risks. For these and other analysts, risk is the dominant cultural theme of the late $20^{\text {th }} \&$ early $21^{\text {st }}$ centuries. In his landmark book, Risk Society: Towards a new modernity, Beck (1992) argued that these risks are continually increasing, that they are not equitably distributed, and that alongside the problem of the sharing of wealth across communities and nations, global systems now face the challenge of the distribution of risk, particularly across different socioeconomic levels. A major point of Beck's thesis is that whilst humans have always faced risks, in recent times the nature of these risks has changed in the extent to which they are man-made risks, which accompany technologies and products usually based on new scientific knowledge. It is this link with scientific knowledge which makes Beck's thesis of interest to science educators.

Beck's thesis could be described as alarmist, since he refers to 'irreversible harm' (1992, p. 23) and 'apocalyptic catastrophe' (p. 60). However, one can find evidence that people generally are concerned about proliferating man-made risks, such as the side effects of medications, of mobile phones, or GM foods. Currently there is community concern about nanotechnology related to the behaviour of extremely small particles in the human body. There are also more longstanding concerns for some groups about the risks of nuclear 
power, of living near high voltage power lines, mobile phone towers or toxic waste dumps, all of which are associated with scientific 'progress'. Many people struggle with these new uncertainties, often in the context of personal decision making. Giddens (1990) sees successful existence in modern society as:

depending simultaneously on trust in proliferating expert systems on the one hand and a deepening reflexivity at both an individual and an institutional level on the other, as citizens increasingly monitor, question, demand justification and accountability from, and otherwise try to cope with a world of increasing uncertainty and risk. (1990, p. 88)

Citizens constitute an "alert and critical public", seen by Beck (1992, p. 19) as evidence of what he theorises as the developing "reflexivity" of late modernity, whereby "questions of the development and employment of technologies (in the realms of nature, society and the personality) are becoming eclipsed by questions of the political and economic 'management' of the risks of actually or potentially utilized technologies” (p. 19).

Scientific knowledge has special significance in relation to assessments of risk. Beck observed that public debates around environmental issues are framed in terms of the formulas of natural science, with social, cultural and political meanings ignored, and that the risks we face "initially only exist in terms of the scientific (or anti-scientific) knowledge about them” (p. 
23, italics in original). He went further to say that "because the risks are imperceptible in most cases, they require the 'sensory organs' of science - theories, experiments, measuring instruments - in order to become visible or interpretable as hazards at all” (p. 27).

Similarly, Irwin and Wynne (1996) noted that on most socioscientific issues scientific knowledge is central to debates in the public domain, playing an important role in the structuring or 'framing' of the discussion. They see this as highly problematic because although this scientific framework is presented as value free, it is in fact "unavoidably social as well as technical" (p. 2), carrying with it assumptions about the social world (including that of the superiority of scientific knowledge) that may not be shared by many members of the community.

In the context of a risk society, scientific knowledge and knowledge about risks become increasingly important, since knowledge is closely linked to power and control within and over people's lives (Foucault, 2000). This is because science is now implicated in many personal and collective decisions and in many cases people are compelled to defer to scientific experts.

Science educators connect with these concerns through the goal of science education for citizenship and there is 
now a groundswell of support amongst many science educators for this new perspective (Aikenhead, 2006; OECD, 2006; Roberts, 2007). In situations where scientific knowledge and risk are connected, the confidence of young people to participate in decision making and to exert personal control in relation to uncertainty (for example, through making sound risk assessments) may link back to their schooling. However, where scientific knowledge is connected with risk, this is not the reliable or 'certain' knowledge of traditional science classrooms, but science surrounded by uncertainties, and this constitutes new territory for science educators.

In this paper I consider various aspects of this situation. Firstly, I explore how teaching about risk offers several new challenges to science educators. I then examine how risk has appeared in the science education literature in the past. Conceptions of risk necessarily underlie how we engage with the topic so I present an overview of some current thinking about risk and suggest an approach for school science. I then introduce public understanding of science research and outline some studies which demonstrate the role of risk in lay adults' engagement with the scientific knowledge of contemporary issues. This underlines the importance of including risk understanding in science education, if we are serious about the goal of science education for citizenship. I then consider how risk understanding might become part of school science curricula and 
suggest how future research might support this inclusion.

\section{How teaching about risk challenges school science education}

Teaching about risk involves three significant new challenges for science teachers. There is firstly the challenge of acknowledging and dealing with the uncertainties of scientific knowledge. The second is to engage with the power and limitations of science in social contexts. These two challenges lead to the third challenge, of changes which would be required in science pedagogy if we are to engage effectively with these dimensions of science in school classrooms. I shall consider these three challenges in turn.

\section{Uncertainty}

There are many dimensions of uncertainty in the construction and application of scientific knowledge, but two are of particular interest here. The first is the uncertainty that complexity brings. Real world contexts are complex; multiple variables interact and simple linear, 'causal' relationships rarely exist. Despite this, school science presents the investigation of phenomena mainly in terms of controlling variables in order to demonstrate a direct relationship between cause and effect. At the same time school science focuses strongly on decontextualised content or concept knowledge. These characteristics of school science 
make the task of applying it in real world contexts immensely difficult.

Research in the public understanding of science has drawn attention to the gap between abstract scientific knowledge and everyday life contexts. In their landmark group of studies, Layton, Jenkins, MacGill and Davy (1993) focused on the usefulness of scientific knowledge for adults trying to solve problems. Participants included parents of Downs syndrome children seeking help with child-raising, elderly people coping with domestic heating and residents concerned about the safety of living near a nuclear re-processing plant. Their findings highlighted "the fragility of much of the available science and its inability to provide unambiguous answers to questions asked" (p. 118). This research demonstrated that science does not operate in the real world as the objective, authoritative body of knowledge which is its most frequent representation, particularly in formal schooling. This conclusion was further supported by Irwin and Wynne's (1996) group of nine studies across a range of contexts. This foundational work and more recent public understanding of science research is important for science educators because it reflects back to us the difficulties of applying school science in everyday contexts which may suggest reasons that students do not see science as relevant in their lives. 
A second kind of uncertainty increasingly encountered in the wider community is the uncertainty of science-inthe-making. This kind of science is often still being contested within the scientific community, with disagreements about the content or interpretation of experimental results; or commercially funded scientists may present findings in a different light from government funded researchers. This is puzzling to many who do not understand the legitimate role of argument and debate in the construction of scientific knowledge. This kind of science features frequently in the popular media yet is rarely encountered in science classrooms. Examples include the ongoing reports of conflicting research findings relating to global warming and climate change, GM crops and foods, mobile phones, dietary influences, high voltage power lines and various forms of waste disposal.

These two kinds of uncertainty - the complexity of contexts and contestation within science - commonly face adults in the community engaged in decisionmaking on problems or issues in which scientific knowledge plays a role. If science education is to provide students with useful knowledge involving science it now needs to engage with these uncertain dimensions. Acknowledging the uncertainties of scientific knowledge is not to decrease its value. It is not to deny the reliability of much scientific knowledge, the wealth and wonder of the vast number of scientific 'discoveries' or the crucial role that science plays in 
problem solving. School science, however, has rarely acknowledged the uncertain dimensions of science and there now seem to be important consequences of failing to do so. It is in relation to decision making where scientific knowledge is uncertain that risk understanding can make a significant contribution.

Science in society

A second challenge in teaching about risk is to acknowledge the power and limitations of science in a social context. Here the concern is to locate scientific knowledge in its wider setting and to acknowledge that a variety of stakeholders may represent a variety of perspectives on the contribution that scientific knowledge can or should make to solving a particular problem. Scientific knowledge can be powerful but should not be thought of as automatically providing solutions to problems. Understanding of science concepts is often important for making such judgments but social and cultural considerations (including lay knowledges) also need to be taken into account. Science is traditionally presented as value-free knowledge but scientists routinely make assumptions and value judgments about uncertainties which are black-boxed into their research. Freudenberg (1988) gives an account of how this happens, detailing potential sources of error in technical judgments about risk. He suggests that the dichotomy between "real" and "perceived" risk is less "real” than is often assumed. 
To meet the challenge of addressing the limitations as well as the power of science, it needs to be presented in schools as a particular social practice with particular values, as well as a body of knowledge. This then connects science with society and social influences can be more readily acknowledged and examined.

Teaching about risk thus challenges science educators in these two important ways - firstly, to acknowledge the complexity of contexts in which science is applied and the contested nature of new science or science-inthe-making. Secondly it challenges teachers to acknowledge the power and the limitations of science in social settings. But a potential reward of contextualising science in this way includes students having greater interest in science as a useful epistemological tool for solving difficult and important problems.

\section{Pedagogy}

Acceptance of the two challenges just described confronts science educators with a third area of challenge, which is pedagogy. Traditional approaches to pedagogy in science classrooms have been authoritarian. However, contemporary socioscientific issues cannot be 'taught' in the usual way since there is not always certain knowledge to be transmitted. Rather, ambiguity and uncertainty must be tolerated and room made available for individual interpretations of a range of data, including personal and sociocultural 
perspectives. It is in these contexts that risk understanding will be relevant and useful, particularly where decision making is required. In this kind of science education, the role of established concept knowledge will not diminish, but efforts towards understanding it are likely to be more purposeful because it has a clear role as an epistemological tool to clarify issues and assist in decision making.

In the growing domain of research into the inclusion of socioscientific issues in classrooms, science educators have begun to examine new pedagogical approaches. Early articles have suggested teaching guidelines (e.g. Van Rooy, 1994; Ratcliffe, 1997; Dawson, 2001); some researchers have explored science teachers' views of this domain and their responses to initial experiences of dealing with socioscientific issues in classrooms (e.g. Cross \& Price, 1996; Levinson \& Turner, 2001; Bryce \& Gray, 2004; Lee \& Witz, 2008)). Working with a small group of teachers, Bartholomew, Osborne \& Ratcliffe (2004) examined some of the difficulties they faced in teaching 'ideas about science'; they identified five dimensions of effective practice but concluded that what is required in this domain involves a significant change in the culture of science teaching. In relation to biotechnology issues, France (2007) has drawn attention to the influence of teacher conceptions of biotechnology and their own positioning choices on how they engage students with contemporary issues in this field. At the same time appropriate pedagogical 
models are being theorised (e.g. Oulton, Dillon \& Grace, 2004; Levinson, 2006).

From this early research it is clear that much work needs to be done to prepare science teachers to engage with socioscientific issues and dimensions such as risk in classrooms. Evaluation of the UK national curriculum Core Science (UYSEG \& Nuffield Foundation, 2007), which is based on contemporary socioscientific issues, has drawn attention to the need to develop new science teaching skills if reforms of science education towards the goal of citizenship are to proceed effectively. Pedagogy for contemporary issues must incorporate a contemporary view of the nature of science. Driver, Newton \& Osborne (2000) have demonstrated how such a view must give a central place and role to argumentation. Argumentation studies constitute a growing domain of research in science education (reviewed by Driver et al., 2000); these studies involve students engaging with science content and socioscientific issues.

The development of argumentation and small group discussion skills are likely to assist students to develop confidence in dealing with issues involving uncertain or controversial science. Collective argumentation (Brown \& Renshaw, 2000) is an innovative pedagogy based on the idea of 'science as progressive discourse' (Bereiter, 1994). In this approach Brown and Renshaw sought to create "more diverse communicative spaces in the 
classroom, that is, spaces for speaking and engagement that differed from the typical IRE [initiation, reply, evaluation] formats in classrooms where teachers do the majority of talking and thinking” (p. 53). In collective argumentation students establish and follow rules of discourse for the discussion of novel and complex problems. This approach has shown promise in the context of mathematics classrooms for developing the kind of collaborative discussion skills important in relation to citizenship.

Fensham (2008) has drawn attention to the complexity of important world issues which face future citizens, noting that dimensions beyond scientific knowledge need to be included in classroom discussions in order that students are not give a 'science-centric' or limited technical view of the problems. This challenges science educators to draw on expertise from other disciplines. Team teaching within a school is a possible approach. Although significant barriers to this have been reported, recent middle years schooling reforms have embraced team teaching as fundamental to engaging adolescents (Jackson \& Davis, 2000). Such a cross-disciplinary move in science education would mirror suggestions by Funtowicz \& Ravetz (1993) for a 'post-normal' science. Like Beck, these writers have argued that the novel risks that science has created (some with high stakes) need a new kind of social response which involves not only scientists but members of the wider community. Funtowicz \& Ravetz call this 'an extended 
peer community', a multi-disciplinary model which includes lay knowledge. A similar perspective reflected in classrooms might engage students in lively debate and result in a better understanding of the vital role science can play in solving important problems, balanced by an awareness of what its limitations and uncertainties are.

\section{Risk in science education}

Writers in science education have previously acknowledged that dealing with uncertainty has become a feature of adult scientific literacy (for example, Cross, 1993; Thomas, 1997; Millar, 1997; Jenkins, 2000; Ryder, 2001). Jenkins (2000) has argued for a paradigm shift in science education which addresses the fact that "the world proves to be much more complicated, uncertain and risky than school science encourages pupils to believe, and the power of science to explain, predict and control turns out to be severely limited.' (p. 211). He suggests that including risk assessment in science education is important because this context of uncertainty and complexity is where most students will ultimately encounter science in their lives. Ravetz (1997) has also argued a need for science education to reform in ways which embrace uncertainty, arguing that "our uncertainty, and indeed our ignorance, are no less relevant than our knowledge”. He has observed that although science curricula have changed over the years there has been "a systematic exclusion of 
uncertainty as an aspect of the scientific knowledge that we possess.” (p. 7)

The understanding of risk has not been a focus in science education policy documents in the past, despite calls for reform increasingly directed towards engaging with personal and collective decision making on issues involving science (AAAS, 1989; Millar \& Osborne, 1998; Goodrum, Hackling \& Rennie, 2001; Tytler, 2007). This recent perspective has been called science education for citizenship, as outlined, for example, by science educators in Science and the citizen: For educators and the public (Cross \& Fensham, 2000). It is part of what Roberts (2007) has recently called Vision II of scientific literacy, which looks outward from science itself to situations in which science plays a role, in contrast to Vision I, which focuses on the knowledge and processes of science itself. One motivation for this direction of reform is the making of science education more related to people's lives.

Some researchers have examined student discussion of socioscientific issues in science classrooms (e.g., Fleming, 1986a,1986b; Solomon, 1990; Driver, Leach, Millar \& Scott, 1996; Ratcliffe, 1997; Zeidler, Walker, Ackett \& Simmons, 2002; Hogan, 2002; Sadler, Chambers \& Zeidler, 2004; Lewis \& Leach, 2006; Dawson \& Venville, 2008). However the role of risk understanding and risk judgment has rarely been addressed in these studies. A notable exception is 
research by Kolstø (2006) in which students' discussions of the safety of high voltage power lines were examined. Scientific risk estimates were provided, along with economic, geographic, psychological and political information. All students used the risk information and it proved to be central in their decision making. Kolstø concluded that science education has an important role to play in developing students' understanding of the concepts of risk and uncertainty.

The first suggestion to include risk understanding in school science was probably made by Howes (1975) in relation to the discussion of nuclear power hazards with upper secondary students. Subsequently Eijkelhof (1986) outlined reasons for the inclusion of risk assessment in science curricula. He argued that scientific information is often essential in decisions about risk issues, and that these issues provide a context for consideration of science-society interactions and an opportunity for students to face challenging questions with worthwhile answers. Eijkelhof developed a Physics teaching unit on dealing with the risks of ionising radiation, which he trialled and evaluated with 25 classes. He found that students demonstrated the capacity to make risk judgments which matched actual risk statistics.

More recently the topic of risk has begun to appear in a few school science curricula. The Science Education for Public Understanding Program (SEPUP), an issues- 
based science curriculum for Years 6-12 established in the US in 1987, includes a module on decision making which deals with probability and risk assessment. Also in the US, risk is approached from the perspective of toxicology in a module in the Cornell Scientific Inquiry curriculum series (Trautmann, Carlsen, Krasny \& Cunningham, 2001) which aims to enable high school students to conduct authentic environmental research. An optional course in the UK for 16-17 year olds, AS Science for Public Understanding (Hunt \& Millar, 2000 ), introduces basic risk understanding in a topic on health risks and applies these ideas across other topics. More recently in the UK risk has been included as one of six "ideas about science" in Core Science, a compulsory subject for 15-16 year olds in the $21^{\text {st }}$ Century Science curriculum (Millar, 2006). Core Science is focused principally on the needs of citizens as 'consumers' rather than 'producers' of scientific knowledge; it has a central concern with decision making involving contemporary science. The course has been trialled and evaluated and is now undergoing wider implementation. Early research has reported success in addressing student engagement with science but risk understanding did not improve. Teachers reported the challenging nature of developing new pedagogic strategies and of becoming more confident in teaching 'ideas about science' such as risk, in contrast to traditional science concepts (UYSEG \& Nuffield Foundation, 2007). 
Solomon (1990) has long argued for the discussion of contemporary issues in science classrooms, and recently suggested that the topic of risk offers a way for science educators to link the cognitive and affective domains in science teaching, since it lies in the boundary region of science and the humanities (Solomon, 2003). It may thus offer an effective source of engagement in the classroom for students currently disaffected with scientific knowledge because it does not seem relevant or useful in their lives. Cross (1993) saw risk as a challenge to science education because the field of risk assessment shows how scientific methodology merges with value judgments about uncertainties. He reflected on approaches to teaching about risks, noting the difficulty for teachers in dealing with the problematic nature of risk assessment.

Thus some science educators have engaged with risk understanding, but it has not been included in science curricula generally and little research has yet focussed on students' understanding of risk or the role that risk might play in decision making on contemporary issues in science classrooms.

Caution has been urged by Donnelly (2004, 2007), however, as to the extent of 'humanizing' the science curriculum by including topics such as risk. He argues that in re-positioning itself in terms of the humanistic, liberal tradition of education, science may lose its distinctive contribution to learning as a unique body of 
knowledge. In his view "an imaginative, effectively taught and coherent account of substantive scientific understanding of the material world must stand at the core of the science curriculum" (2004, p. 781). He has questioned the inclusion of risk as one of six 'ideas about science' in the UK national curriculum mentioned earlier and argued that such themes should be subordinate to the foundational purpose of science, "to promote a critical understanding of scientific knowledge proper and its place in the world" (2007, p. 33). This view stands in contrast to Aikenhead's (2006) call to researchers to apply humanistic perspectives to renegotiate the culture of school science, his position originating from an understanding of science as culture and learning science as border crossing into its culture.

Risk understanding is thus perhaps a controversial topic to be considered for inclusion in science education curricula. It is, however, now a widely applied response to uncertainty in contemporary society across a range of contexts and uncertain or contested science is increasingly a part of public discourse. Rather than undermining science in the eyes of students, setting school science in this wider context can highlight what science has to offer to problem solving in terms of evidence-based knowledge.

\section{Conceptions of risk}

In developing an approach to risk, science educators will be influenced by their conceptions of risk and 
particularly how its connections with scientific knowledge are viewed. A range of conceptions and what might be appropriate in science classrooms are now considered.

Since its beginning barely 20 years ago, the field of risk research has been dominated by the physical and life sciences, with a focus mainly on measurement. Here risk assessment is based on the relative frequency of an event measured over a past time period or quantification of the relationship between a potential risk agent and observed physical harm. However the social sciences have become increasingly involved, with growing interest in risk management and risk communication (Golding, 1992). Defining risk as "the possibility that an undesirable state of reality (adverse effects) may occur as a result of natural events or human activities”, Renn (1992, p. 56), described a spectrum of perspectives on risk, largely based on the various academic disciplines. He described seven conceptions of risk arising from these different perspectives. Three of these (the actuarial approach, the toxicological and epidemiological approach and the engineering approach) he defined as "technical" conceptions in which risk is seen as an objective property of an event or an activity, measured as the probability and magnitude of possible harm. Beck (1992) defined risk as "a systematic way of dealing with hazards and insecurities induced and introduced by modernization itself” (p. 21). 
By contrast, risk has also been conceptualised as culturally or socially constructed (this includes economic, psychological, social and cultural perspectives). In this view risk conceptions differ considerably amongst social and cultural groups. Foundational work was done by anthropologist Mary Douglas, who critiqued the use of the term "risk" for its universalising tendency, "its abstractness, its power of condensation, its scientificity, its connection with objective analysis" (Douglas, 1992, p. 5) and proposed that cultural influences play a major role in how people focus on particular dangers in their lives. Douglas observed that we judge risks according to knowledge/information, the kind of people we are and the influence of our cultural beliefs. This applies to all modes of risk assessment including technical/scientific judgments, which thus include value-laden assumptions despite claims of objectivity.

Within a sociocultural framing of risk, Lupton and Tulloch (2002) have examined "the narratives, epistemologies, discourses, rhetorical moves, choices of 'rational arguments' and courses of action which people use to organize 'risk' as a cultural concept.” (p. 320). They also explored the extent to which people see risk in global, regional or local terms or simply as a result of their own personal life circumstances, motivated by Beck and Giddens' claims of a shift in risk conceptions towards larger scales. From a small study (74 young to 
middle-aged adult interviewees) in an Australian setting, in both urban and regional locations, they reported a dominant tendency to see risk as negative, even a synonym for danger, associated with the emotions of fear and dread. At the same time, however, risk had positive connotations for some participants and many shared a view that risk is an inherent part of human existence. Lupton and Tulloch interpreted these responses as a challenge to Beck's somewhat gloomier picture. Speaking of changes in their risk perceptions over time, most participants illustrated a view of risk as subjective. Associated with this was the opinion that engaging with risk is an important life challenge which develops one's knowledge of self and the world. Environmental risks were mentioned by far fewer people than social divisiveness and structural economic problems, an interesting reflection on Beck's thesis. Also in relation to Beck's account, here there was little sense of external forces producing risks. Instead the interviewees tended to represent themselves as "autonomous actors, rationally making decisions about which risks they choose" (p. 331). This supported Beck's tenets of individualization and reflexivity, as "participants demonstrated an individualizing approach to risk but also a politicized social consciousness of the structural underpinnings of risks that required government intervention” (p. 332)

A focus on the psychological dimension of people's ideas of risk constitutes a psychometric perspective on 
risk research, developed by Slovic (1992, 2000). From this perspective it is argued that people's perceptions of risk arise from the interaction of values with world views, gender and trust and that all of these factors need to be taken into account in conceptualising risk. This kind of research explores people's expressed preferences for various kinds of risk/benefit choices. Data are usually collected on large numbers of activities and statistical methods are applied. People are asked to characterise hazards by rating them according to qualities such as voluntariness, catastrophic potential, controllability and dread. This approach assumes that risk is inherently subjective and does not exist outside of us in any 'real' or objective sense. It is believed that with well-designed surveys useful models can be constructed which will predict the responses of individuals and societies to the hazards they encounter. The subjectivity of risk perceptions extends to scientists and engineers, whose quantitative risk estimates are seen to be based on theoretical models whose structure and assumptions depend upon judgment and are thus influenced by psychological, social, institutional and cultural factors.

The dichotomy between objective and subjective interpretations of risk was challenged by Wynne (2001) in the context of public responses to GM crops and foods. Wynne noted that 20 years of social science research has effectively challenged the dichotomy and yet it is still being promoted in relation to GM issues 
through the binary of risk versus ethical concerns. He sees the dichotomy as patronizing the public through the portrayal of their risk concerns as solely about ethics and intellectually vacuous. Wynne argues that what is missing from so-called 'objective' assessments of risk is the unknown uncertainties and he notes an unwillingness on the part of scientists and their institutions to acknowledge the limits and contingencies of the knowledge they advance (see also Freudenberg, 1988).

An important concept when dealing with situations of uncertainty and ignorance is the precautionary principle. This approach to risk applies where there are threats of serious or irreversible damage and reliable knowledge is not available. The lack of full scientific certainty is rejected as a reason for postponing preventative action (Harremoës, Gee, MacGarvin, Stirling, Keys, Wynne, \& Guedes Vaz, 2002). In their report for the European Environment Agency, Harremoës et al. presented 12 case studies of well known hazards to workers, the public and the environment where substantial harm might have been avoided or reduced if the precautionary principle had been applied.

Thus risk can be approached in a variety of ways. As noted earlier, the conception of risk traditionally associated with science is a technical conception, in which risk is seen as an objective property of an event 
or an activity, measured as the probability and magnitude of possible harm. However, science education which addresses contemporary socioscientific issues (in which risk is likely to be encountered) is concerned with the goal of citizenship. This sets science in its sociocultural context and an integrated conception of risk, including scientific, personal and sociocultural dimensions, would seem appropriate.

Lupton and Tulloch's (2002) study above suggests an approach to risk which may prove useful with school age students. For many participants in their study risk is an important life challenge which develops their knowledge of self and the world. This was also demonstrated by Denscombe (2001), who found that the risk-taking behaviour of smoking by adolescents can play an important role in the construction of their identity, both for self and others. Recent research involving young adults and scientific research into the possible health effects of mobile phones (Christensen, 2007) reports an interest in risk-taking and risk comparison. In this research risk talk was spontaneously introduced by participants into almost all of the focus group discussions and was arguably an important influence on their attitude to the science presented to them. Since risk might be an important identity resource for many students, it may be necessary to connect with them through psychometric (subjective) and sociocultural aspects. The scientific/technical conception of risk could be presented in science classes 
as an important part of scientific knowledge and a useful epistemological tool to assist in sound decision making, including aspects described later in this paper.

Subjective framings of risk become evident when socioscientific issues are debated and these are often at odds with expert scientific thinking. Social scientists have begun to explore this terrain. What follows is not a literature review but rather a sampling of public understanding of science research which demonstrates the strong links between scientific knowledge and risk now becoming evident in community responses to science.

\section{Risk in public understanding of science studies}

Public understanding of science research is a relatively new domain of research which examines lay adults' interactions with science in community settings. It is of interest here because the context frequently involves contested or uncertain science and its association with risk, and because these researchers often draw implications for science education. Risk has not been a focus of early work in this area but attention was paid by foundational researchers to the role of trust in the often-problematic relationship between the public and expert scientific knowledge. Layton et al. (1993, p. 122) observed that "people do not encounter scientific knowledge as free-floating and unencumbered by social and institutional connections. The questions, 'From whom?' and 'From where? From what institutional 
source?' are central to judgments about the trustworthiness and reliability of the knowledge." In many instances participants' responses to the science presented to them by experts were crucially affected by how they perceived the presenters, as sharing or not sharing their particular perspective on the problem at hand. In the more recent public understanding of science studies which I describe here risk and trust are intertwined, as Beck and Giddens have noted they often are in situations of uncertainty. These studies reflect back to science educators the real world science that their students are increasingly likely to encounter in their future lives and the need to encompass risk in the discussion of socioscientific issues.

Evidence of new interest in the relation between science and risk is the establishment of the Programme on Understanding Risk (2001-2005) in the UK, funded by the Leverhulme Trust. This project (Poortinga \& Pidgeon, 2003) aimed to develop theoretical understanding of public framings and attitudes towards science and risk issues. Surveys were conducted by face-to-face interview of 1547 adults across the UK on their perceptions of five contemporary issues which raise prominent public policy questions - climate change, mobile phone radiation, radioactive waste, GM foods and genetic testing. These quantitative data were then "triangulated" with a series of qualitative studies. The participants' perceptions of the five risk cases were investigated using concepts from the 
sociological/psychometric paradigms of risk; no scientific/technical risk estimates were used. Personal and social interests were included in the rating scheme, along with interest, affect, the role of culture, and environmental values. Perceptions of risks versus benefits were also examined and attitudes towards science in general were explored. Most participants held a positive view of science but almost $40 \%$ agreed that "We put too much trust in science", which the researchers interpreted as meaning that people show a degree of "critical trust" towards science, a feeling that science should not be trusted blindly. The five risk issues were not rated ahead of other personal issues, such as health, partner and family and personal safety. This finding challenges Beck's suggestion that these 'new' risks loom large in public consciousness. However a large majority of participants indicated that they were fairly or very interested in all five risk cases and most wanted more information about the risks. Considerable concern was expressed about funding affecting the independence of scientific research. Trust in regulatory authorities to control risk was generally not high, and overall people felt a need for independent organisations to regulate the risks of these five cases. These researchers reported that in the field of risk research "there is a growing recognition that trust in (risk) regulators is an important factor in reactions to and acceptability of risk" (p. 34). They also noted that trust in a source is a prerequisite for risk 
communication - this includes scientists as well as regulators.

A second UK study commissioned by the Department of Health (Petts, Wheeley, Homan \& Niemeyer, 2003) was motivated by a need to understand 'risk and science' in the context of public health education. The aim of the study was "to identify and understand individuals' risk literacy and its impact on risk information requirements.” (p. v). The issues chosen for this research were MMR, air pollution and mobile phones. Eighteen groups of adults (186 in total) participated in two focus group discussions which also involved scientific experts. Discussion centred on one of the three issues, on the information provided, and on the information preferences of the participants. These researchers linked risk with science in their conceptualization of 'risk literacy', which they defined as "the nature and breadth of individuals' underpinning knowledge relating to science in general, including concepts of uncertainty in risk assessment, and how they make sense of the health risk issues in particular" (p. 33). They linked the literatures of risk communication and the public understanding of science, and drew implications for science education, arguing that "Education has an important role to play in raising risk literacy. Teaching 'pure' science needs to be complemented by understanding of risk and developing competencies for dealing with risk in adult 
life.” (p. vi). They urged a focus on 'science and risk' literacy within schools.

The linking of science, risk and trust is also demonstrated in a recent New Zealand study, in which Hipkins, Stockwell, Bolstad and Baker (2002) conducted telephone surveys of 801 adults, with the aim of investigating "the thoughts, feelings and attitudes which contribute to participants' views of science within a particular discussion context” (p. 76). They reported that a significant degree of mistrust of science became evident at a relatively early stage of their research. In order to explore this lack of trust further, they conducted focus groups with 21 survey respondents to consider the science of potential mobile phone health risks. Participants were provided with basic conceptual information relating to mobile phone radiation and were introduced to the SARS protocol used by scientists to test the microwave output of mobile phones. Focus groups discussed the issue of mobile phone safety and then responded to specially written 'news brief' type reports of six actual scientific studies and six Internet items describing scientific research on mobile phone effects. A key finding was that most participants recognize that new developments in science and technology are important to the economy and they value the advancement of knowledge. However, many showed a high level of concern about the consequences of new developments. 59\% of the participants felt scientists should be kept under strict 
government control. Hipkins et al. reported that this concern is exacerbated by the conflating of science and business interests, and a high level of awareness of past dishonesties by some scientists and/or their funding bodies. They concluded that issues of trust "are likely to strongly shape public perceptions of science where there are obvious commercial gains to be made from the products of research being carried out and/or where the research is about the safety of existing applications” (p. 112). Some participants saw openness about uncertainty as evidence of honesty on the part of scientists. The study did not produce mobile phone risk assessments by the participants but demonstrated that their attitudes to the science of mobile phone risk was related to their feelings of trust towards scientists.

As well as studies addressing a range of public concerns, some researchers have focussed on particular issues such as GM foods (Shaw, 2002; Tulloch \& Lupton, 2002) or global warming (Bulkeley, 1997). Whilst the focus of such studies is usually people's perceptions of the phenomenon itself, risk and trust inevitably arise in the discussions reported. An example is Shaw's in-depth exploration of lay understandings of genetically modified food. She concluded that two central concepts emerging from the context were knowledge and risk and that closely related to these was the notion of trust. Across all the interviewees (32 adults, aged 15-85, over a range of socio-demographic backgrounds) concerns centred on 
the uncertainty of "expert" scientific knowledge participants perceived the knowledge of genetic modification to be complex and uncertain, even for scientists, and they noted similarly the uncertainty of knowledge of present and future risk.

In presenting background to the study, Shaw described how scientific arguments about risk have now entered everyday discourses about food. She notes that "the specific and recurring use of the concept of risk in such discussion, and the framing of food debates as "risk" issues, have become ever more common." (p. 274). UK and European governments have responded to public concerns with new regulatory bodies to protect public health and restore confidence in food and "risk is central to the work of these new food agencies, and the challenges of assessing, managing, and communicating risk in the face of scientific uncertainty are increasingly recognized" (p. 274). Shaw concluded that not only has food become a political issue in recent years, it is also an arena where "the concept of risk has become increasingly central to scientific, political and lay discourses" (p.274).

Further strong evidence for the usefulness of risk understanding was described by Duggan \& Gott (2002) in an empirical study which investigated the kinds of scientific knowledge needed by lay adults in personal decision making on three local issues: the emission effects of burning recycled liquid fuel in a local cement 
kiln, the siting of a mobile phone base station near a primary school and the choice of immunization of young children. These researchers found that understanding of the concept of risk and the associated concept of probability was 'crucial' for personal decision making on all three issues. Parents concerned about immunization based their decision on a balancing of risk and in all three cases the precautionary principle was discussed.

Public understanding of science research has been linked with school science by Ryder (2001) through his analysis of 31 public understanding of science studies (some involving well-established science and others contested science), in order to develop a framework for 'functional scientific literacy'. This provides a useful starting point for school science concerned with citizenship. Content knowledge tended not to be central to decision making (though it was important on some issues); knowledge about science proved to be more useful. Ryder argued that six categories of knowledge are necessary for effective lay interactions with scientific knowledge: subject matter knowledge, collecting and evaluating data, interpreting data, modelling in science, uncertainty in science and science communication in the public domain. Ryder analysed issues relating to uncertainty which were significant for individuals in the studies, concluding that important understanding relates to risk - knowing that decisions may need to be made of the basis of risk estimates and 
to recognise that in some cases risk estimates will not be available.

The studies described in this section, and Ryder's survey, demonstrate that in the wider community scientific knowledge is frequently associated with judgments of risk and trust. It would thus seem important to include these dimensions of risk and trust in school science as part of understanding the nature of science, if it is to prepare students to deal with contemporary socioscientific issues in their future lives. How risk understanding might be addressed is now considered.

\section{Towards risk understanding in science classrooms}

Science education researchers have been advocating the discussion of contemporary socioscientific issues in science classrooms for some time and a significant body of research has now begun to accumulate (Sadler, 2004). Early findings suggest that potential learning from such discussions includes content knowledge, argumentation skills and understanding of the nature of science. Some studies mentioned earlier (Eijkelhof, 1986; Kolstø, 2006) have demonstrated that secondary school students are capable of dealing with risk information. It is not difficult to envisage the teaching of basic concepts of risk and risk assessment in these contexts, particularly where they involve personal or collective decision making. Both Kolstø (2006), and Duggan \& Gott (2002) in their study involving adults, 
found that risk was central to decision making. Thus it clearly has the potential to play an important role in some issues.

Useful content could include the quantification of risk through probability calculations based on past events, the concepts of absolute risk and relative risk, risk comparison, and risk/benefit analysis. Risk/benefit analysis needs to include the 'halo effect', described by Alhakami \& Slovic (1994) as the inverse relationship between perceived risk and perceived benefit. This involves people judging objects, people or things in terms of personal attitude towards them. In recent research concerned with young adults and the uncertain science of mobile phone health risks (Christensen, 2007), the strong dependence of almost all of the participants on their mobile phones for social networking was a powerful influence on their responses to the contested science and their risk assessments.

The sociocultural dimensions of risk which should be considered alongside technical approaches include the qualitative nature of risks (for example, their voluntariness, familiarity, controllability, history, fearfulness, and the 'dread factor') and the influence of these factors on perceptions of risk. An alternative when statistics from past events are not available and scientific knowledge is uncertain, is to consider the precautionary principle. This is of increasing interest to many people who perceive that the capacity of science 
to create new products and technologies does not seem to be matched by an ability to foresee harmful consequences (Harremoës et al., 2002). On issues where outcome possibilities are still unknown, the place of ignorance or not knowing is also worthy of discussion. Wynne (1993) has distinguished risk, uncertainty, ignorance and indeterminacy as follows:

- Risk: system behaviour is known and outcomes can be assigned probabilities

- Uncertainty: important system parameters are known, but not the probabilities

- Ignorance: what is not known is not known

- Indeterminacy: causal chains, networks or processes are open and thus defy prediction

It may be useful to include these four kinds of uncertainty in discussions of scientific knowledge in order to challenge the ideology of certainty which currently pervades school science and which can rarely deliver in real world contexts. Different issues could be chosen to illustrate these different scenarios. The important role of ignorance as the starting point of all scientific endeavour can be acknowledged. Risk, uncertainty, ignorance and indeterminacy are not traditionally ideas about science but in the light of the philosophy and sociology of science studies of recent times and sociological analyses such as those of Beck and Giddens mentioned earlier, they now constitute an important part of understanding the nature of science relevant to many contemporary issues. 
Many articles in the popular media concerned with science and health mention risk (Millar, 2006). In these articles two factors are often correlated, but connected causally only by inference, without the provision of evidence of causal mechanisms. Thus understanding the difference between correlation and cause would seem to be useful for interpreting such media reports. Official medical information is also often accompanied by risk statistics. For example, two new health sites offer personal risk analysis for breast cancer (http://www.nbcc.org.au/risk/) and heart disease (http://www.cvdcheck.org.au) This demonstrates the usefulness of understanding risk ideas for accessing important health knowledge now in the public domain.

In linking his analysis of 31 public understanding of science case studies (mentioned earlier) with school science curricula, Ryder (2002) suggested the importance of providing students with a basic scientific vocabulary concerning ideas such as validity, reliability, sample size, variables, modelling assumptions and approximations, correlation, causation, risk and scientific uncertainty. Critical thinking can develop from these ideas. How risks are estimated technically can be considered, for example, Osborne (2007) notes the over reliance of risk assessments on mortality rates rather than injuries. Also concerned with the popular media, Bennett, Coles and McDonald (1999) have noted that media reporting of relative risks can be seriously misleading, directing attention towards 
smaller absolute risks at the expense of greater ones. This underlines the importance of understanding the concepts of relative and absolute risk.

\section{Future research directions}

Socioscientific issues vary widely in how they are constituted and what kinds and levels of knowledge are required for students to engage in meaningful discussion about them. Not all issues are likely to engage students and risk will be of varying importance on different issues. Thus in advancing research on the classroom discussion of socioscientific issues mentioned earlier, comparisons could be sought between the differing scenarios, of the role that risk assessment might play. Issues could also be examined in terms of Wynne's four dimensions of uncertainty. This would assist in developing approaches to risk understanding in appropriate contexts.

Although Kolstø and Eijkelhof have demonstrated student capability with risk ideas, students' responses to ideas of risk and uncertainty in relation to science need to be examined further. Research could focus on how students engage with risk ideas across a range of issues. This would elucidate the role that risk understanding plays in the development of students' arguments and decision making, building on Kolstø's (2006) study, which examined the variety of ways in which students used risk in their decision making about high voltage power lines in their local community. 
Solomon (2003) has suggested that risk provides an opportunity to motivate student interest but this will need to be tested. Student interest in risk may not connect with interest in learning more science, especially if the science on offer recommends against a favourite activity in their lives such as mobile phone use or smoking. Early research from the UK $21^{\text {st }}$ Century Core Science implementation mentioned earlier has demonstrated student engagement linked to contemporary issues, but understanding of risk did not show improvement. Reasons for this need to be explored. Resources for $21^{\text {st }}$ Century Core Science offer teachers some approaches to basic risk concepts; research could examine how effective these are in classrooms and whether the concepts are applied by students in subsequent class discussions of socioscientific issues. Most importantly, as described earlier, there are significant challenges for science teachers in engaging with this new 'idea about science', so teacher engagement with risk ideas needs to be explored, perhaps building on the work of Bartholomew et al. (2004) mentioned previously.

In this paper I have considered the role of risk understanding in science education and some evidence suggesting that this is a useful knowledge resource in science education towards citizenship. Ryder (2002) has pointed out that scientific progress on many issues of public concern is likely to be slow, with interim 
pronouncements characterized by uncertainty. This makes the challenge of dealing with uncertainty and risk an important one for future citizens. As Jenkins has observed, if we do not engage in school science with the uncertain science of contemporary issues, we leave students confronted with "two seemingly conflicting, if perhaps overlapping, visions of science: one constructed and institutionalized in the school curriculum, and another which is much less secure and develops from their own, rapidly enlarging experience of the social, physical and emotional worlds which they inhabit." (Jenkins, 2000, p. 209)

The inclusion of socioscientific issues in school science classrooms is a recent innovation and remains controversial. Much discussion and debate is needed in the science education community to examine the goal of science education towards citizenship and much research is needed to examine ways in which contemporary science with its uncertainty and risk may be included in school curricula.

\section{Acknowledgements}

I would like to acknowledge the support of the Griffith University Faculty of Education for their award of a postdoctoral scholarship which made writing possible.

My sincere thanks also to Emeritus Professor Peter Fensham who gave valuable critical feedback on drafts of the paper. 


\section{REFERENCES}

Aikenhead, G. (2006). Science education for everyday

life: Evidence-based practice. New York: Teachers College Press.

AAAS (American Association for the Advancement of Science). (1989). Science for all Americans Project 2061. New York: Oxford University Press.

Alhakami, A., \& Slovic, P. (1994). A psychological study of the inverse relationship between perceived risk and perceived benefit. Risk Analysis, 14, 10851096.

Bartholomew, H., Osborne, J., \& Ratcliffe, M. (2004).

Teaching students "ideas about science”: Five dimensions of effective practice. Science Education, 88, 655-682.

Beck, U. (1992). Risk society: Towards a new modernity. London: Sage.

Bennett, P., Coles, D., \& McDonald, A. (1999). Risk communication as a decision process. In P. Bennett \& K. Calman, (Ed.), Risk communication and public health. (pp. 207-221) Oxford: Oxford University Press,.

Bereiter, C. (1994). Implications of postmodernism for science, or, science as progressive discourse. Educational Psychologist, 29(1), 3-12.

Bryce, T., \& Gray, D. (2004). Tough acts to follow: the challenges to science teachers presented by biotechnological progress. International Journal of Science Education, 26(6), 717-733. 
Brown, R., \& Renshaw, P. (2000). Collective argumentation: A sociocultural approach to reframing classroom teaching and learning. In $\mathrm{H}$. Cowie \& G. Van der Aalsvoort (Ed.), Social Interaction in Learning and Instruction: The meaning of discourse for the construction of knowledge. (pp. 52-66) Oxford: Pergamom.

Christensen, C. (2007). Waiting for Certainty: Young people, mobile phones and uncertain science. Retrieved from http://eprints.qut.edu.au/16588/, 25 May, 2009.

Bulkeley, H. (2000). Common knowledge? Public understanding of climate change in Newcastle, Australia. Public Understanding of Science, 9, 313333.

Cross, R. T. (1993). The risk of risks: A challenge and a dilemma for science and technological education. Research in Science and Technological Education, 11(2), 171-183.

Cross, R., \& Fensham, P. (Eds.). (2000). Science and the citizen: For educators and the public. Melbourne: Arena.

Cross, R., \& Price, R. (1996). Science teachers' social conscience and the role of controversial issues in the teaching of science. Journal of Research in Science Teaching, 33(3), 319-333.

Dawson, V. (2001). Addressing controversial issues in secondary school science. Australian Science Teachers' Journal, 47(4), 38-44. 
Dawson, V., \& Venville, G. J. (2008) High-school students' informal reasoning and argumentation about biotechnology: An indicator of scientific literacy? International Journal of Science Education, iFirst Article, 1-25.

Denscombe, M. (2001). Uncertain identities and healthrisking behaviour: The case of young people and smoking in late modernity. British Journal of Sociology, 52 (1), 157-177.

Donnelly, J. (2004). Humanizing science education? Science Education, 88(5), 762-784.

Donnelly, J. (2007). Twenty First Century Science Pilot: Evaluation Co-ordinator's Final Report. UYSEG (University of York Science Education Group) \& Nuffield Foundation. Retrieved from www.21stcenturyscience.org, 21 November, 2008. Douglas, M. (1992). Risk and Blame: Essays in cultural theory. London: Routledge.

Driver, R., Leach, J., Millar, R., \& Scott, P. (1996). Young people's images of science (1st ed.). Buckingham, UK: Open University Press. Driver, R., Newton, P., \& Osborne, J. (2000).

Establishing the norms of scientific argumentation in classrooms. Science Education, 84, 287-312.

Duggan, S., \& Gott, R. (2002). What sort of science education do we really need? International Journal of Science Education, 24(7), 661-679.

Eijkelhof, H. (1986). Dealing with acceptable risk in science education: the case of ionizing radiation. In M. J. Fraser \&. A. Kornhauser (Ed.), Ethics and 
Social responsibility in Science Education (pp. 189-200). Oxford, UK: Pergamon Press.

Fensham, P. (2008). Complexity theory: A next step for SSI education and research. Paper presented at ASERA 2008 Conference, July 2-5, Brisbane, Australia.

Fleming, R. (1986a). Adolescent reasoning in scientific issues, Part 1: Social Cognition. Journal of

Research in Science Teaching, 23(8), 677-687. Fleming, R. (1986b). Adolescent reasoning in socioscientific issues, Part II: Non-Social Cognition. Journal of Research in Science Teaching, 23(8), 689-698.

Foucault, M. (2000). Power (Vol. 3). New York: The New Press.

France, B. (2007). Location, location, location:

Positioning biotechnology education for the 21st

century. Studies in Science Education, 43, 88-122.

Freudenburg, W. (1988). Perceived risk, real risk:

Social science and the art of probabilistic risk assessment. Science, 242, 44-49.

Funtowicz, S. O., \& Ravetz, J.R. (1993). Science for the post-normal age. Futures, 25(7), 739-755.

Giddens, A. (1990). The Consequences of Modernity. Cambridge: Polity Press.

Golding, S. (1992). A social and programmatic history of risk research. In S. Krimsky \& D. Golding (Ed.), Social theories of risk (pp. 23-52). Westport, Connecticut: Praeger. 
Goodrum, D., Hackling, M., \& Rennie, L. (2001).

DETYA Report : The status and quality of teaching and learning of science in Australian schools: A research report prepared for the Department of Education, Training and Youth Affairs. Department of Employment, Training and Youth Affairs.

Harremoes, P., Gee, M., MacGarvin, A. Stirling, J.

Keys, B. Wynne, S. Guedes Vaz (Ed.). (2002). The precautionary principle in the 20th Century.

London: Earthscan Publications Limited.

Hipkins, R., Stockwell, W., Bolstad, R., \& Baker, R.

(2002). Common sense, trust and science: How

patterns of beliefs and attitudes to science pose challenges for effective communication: New

Zealand Ministry of Research, Science \&

Technology.

Hunt, A., \& Millar, R. (2000). AS Science for Public

Understanding. Oxford: Heinemann.

Hogan, K. (2002). Small groups' ecological reasoning

while making an environmental management

decision. Journal of Research in Science Teaching, 39, 341-368.

Howes, R. (1975). Radiation Risks - A possible

teaching topic. Physics Education, 10(6), 412-416.

Irwin, A., \& Wynne, B. (1996). Misunderstanding

Science? The public reconstruction of science and technology: Cambridge University Press.

Jackson, A.W., \& Davis, G. A. Turning points 2000:

Educating adolescents in the $21^{\text {st }}$ century. 
Columbus, OH: National Middle Schools Association.

Jenkins, E. (2000). 'Science for all': time for a paradigm shift? In L. R. Millar, J., \& Osborne, J. (Ed.), Improving Science Education: The contribution of research (pp. 207-226). Buckingham: Open University Press.

Kolstø, S. (2006). Patterns in students' argumentation confronted with a risk-focused socio-scientific issue. Science Education, 28(14), 1689-1716. Layton, D., Jenkins, E., Macgill, S. \& Davey, A.

(1993). Inarticulate Science? Perspectives on the public understandings of science and some implications for science education (First ed.). Driffield: Studies in Education Ltd.

Lee, H., \& Witz, K. (2008). Science teachers' inspiration for teaching socio-scientific issues:

Disconnection with reform efforts. International Journal of Science Education (iFirst Article), 1-30. Levinson, R. (2006). Towards a theoretical framework for teaching controversial socio-scientific issues. International Journal of Science Education, 28(10), 1201-1224.

Levinson, R., \& Turner, S. (2001). The teaching of social and ethical issues in the school curriculum, arising from developments in biomedical research: A research study of teachers. London: Institute of Education, University of London and Wellcome Trust. 
Lewis, J., \& Leach, J. (2006). Discussion of socioscientific issues: The role of science knowledge. International Journal of Science Education, 28(11), 1267-1287.

Lupton, D., \& Tulloch, J. (2002). "Risk is part of your life”: Risk epistemologies among a group of Australians. Sociology, 36(2), 317-334.

Millar, R. (1997). Science education for democracy: what can the school curriculum achieve? In P. Levinson, \& Thomas, J. (Ed.), Science Today: Problem or crisis? (pp. 87-101). London: Routledge.

Millar, R. (2006). Twenty First Century Science:

Insights from the design and implementation of a scientific literacy approach to school science. International Journal of Science Education, 28(13), 1499-1521.

Millar, R. \& Osborne, J. (1998). Beyond 2000: Science education for the future. London: King's College London, School of Education, Report of a Seminar Series.

OECD (Organisation of Economic \& Cultural Development) (2006). Assessing scientific, reading and mathematical literacy: A framework for PISA 2006. Retrieved 22 May, 2009, from http://www.pisa.oecd.org

Osborne, J. (2007). Science education for the twenty first century. Eurasia journal of mathematics, science \& technology education, 3(3), 173-184. 
Oulton, C., Dillon, J., \& Grace, M. (2004).

Reconceptualizing the teaching of controversial issues. International Journal of Science Education, 26(4), 411-423.

Petts, J., Wheeley, S., Homan, J., \& Niemeyer, S.

(2003). Risk literacy and the public: $M M R$, air pollution and mobile phones. University of Birmingham: Centre for Environmental Research and Training.

Poortinga, W., \& Pidgeon, N. (2003). Public

perceptions of risk, science and governance.

Norwich, UK: University of East Anglia.

Ratcliffe, M. (1997). Pupil decison-making about socioscientific issues within the science curriculum. International Journal of Science Education, 19(2), 167-182.

Ravetz, J. (1997). Simple scientific truths and uncertain policy realities: Implications for science education. Studies in Science Education, 30, 5-18.

Renn, O. (1992). Concepts of risk: A classification. In S. Krimsky \& D. Golding (Ed.), Social Theories of Risk (1st ed., pp. 53-82). Westport, CO: Praeger.

Roberts, D. (2007). Scientific literacy/science literacy.

In S. Abell \& N. Lederman (Ed.) International Handbook of Research on Science Education (pp.

729-780). Mahwah, NJ: Lawrence Erlbaum

\section{Associates.}

Ryder, J. (2001). Identifying science understanding for functional scientific literacy. Studies in Science Education, 36, 1-44. 
Ryder, J. (2002). School science education for citizenship: strategies for teaching about the epistemology of science. Journal of Research of Curriculum Studies, 34(6), 637-658.

Sadler, T. (2004). Informal reasoning regarding socioscientific issues: A critical review of research. Journal of Research in Science Teaching, 41(5), 513-536.

Sadler, T., Chambers, F., \& Zeidler, D. (2004). Student conceptualizations of the nature of science in response to a socioscientific issue. International Journal of Science Education, 26, 387-409.

SEPUP (Science Education for Public Understanding Program) (1987). Retrieved October 24, 2007, from http://www.lawrencehallofscience.org/sepup/ Shaw, A. (2002). "It just goes against the grain.”: Public understanding of genetically modified (GM) food in the UK. Public Understanding of Science, 11(3), 273-291.

Slovic, P. (1992). Perception of risk: Reflections on the psychometric paradigm. In S. Krimsky \& Golding, D. (Ed.), Social Theories of Risk (pp. 117-152). Westport, CO: Praeger.

Slovic, P. (2000). Perception of risk from radiation. In

P. Slovic (Ed.), The perception of risk (pp. 264-

274). London: Earthscan.

Solomon, J. (1990). The discussion of social issues in the science classroom. Studies in Science Education, 18, 105-126. 
Solomon, J. (2003). Risk: Why don't they listen to us?

Studies in Science Education, 39, 125-141.

Thomas, J. (1997). Informed ambivalence: Changing attitudes to the public understanding of science. In R.Levinson \& J. Thomas, (Ed.), Science today:

Problem or crisis? London: Routledge.

Trautmann, N., Carlsen, W., Krasny, M., \&

Cunningham, C. (2001). Assessing toxic risk.

Arlington, Virginia: NSTA Press.

Tulloch, J., \& Lupton, D. (2002). Consuming risk, consuming science: The case of GM foods. Journal of Consumer Culture, 2(3), 363-383.

Tytler, R. (2007). Re-imagining science education:

Engaging students in science for Australia's future.

Camberwell, Victoria: Australian Council for Educational Research.

UYSEG (University of York Science Education Group) and Nuffield Foundation. (2007). Twenty first century science pilot: Evaluation report. Retrieved from www.21stcenturyscience.org. 21 November, 2008.

Wynne, B. (1993). Uncertainty and environmental learning: Reconceiving science and policy in the preventive paradigm. In T. Jackson (Ed.) Clean production strategies: Developing preventive environmental management in the industrial economy. London: Lewis.

Wynne, B. (2001). Creating public alienation: Expert cultures of risk and ethics on GMOs. Science as Culture 10(4), 445-481. 
Van Rooy, W. (1994). Teaching science using controversial issues: some guidelines to enhance student learning and motivation. Australian Science Teachers Journal, 40(1), 24-27.

Zeidler, D. L., Walker, K. A., Ackett, W. A., \&

Simmons, M. L. (2002). Tangled up in views:

Beliefs in the nature of science and responses to socioscientific dilemmas. Science Education, 86, 343-367. 